ANUARIO DE Estudios MEDIEVALES

49/2, julio-diciembre de 2019, pp. 509-531

ISSN 0066-5061

https://doi.org/10.3989/aem.2019.49.2.05

\title{
ESTRELLA-CORAZÓN, ESTRELLA-CORTADOR: UNA INTERPRETACIÓN NUEVA DEL CONCEPTO DE ESTRELLA-BĀBANI
}

\author{
HEART-STAR, CUTTER-STAR: \\ A NEW INTERPRETATION OF THE CONCEPT OF BĀBANĪ-STAR
}

MONTSE DÍAZ-FAJARDO

Universitat de Barcelona

https://orcid.org/0000-0002-4732-5924

\begin{abstract}
Resumen: Algunos textos astrológicos medievales escritos en lengua árabe aluden a las "estrellascorazones" en referencia a tres estrellas de gran luminosidad pertenecientes a constelaciones del círculo del zodíaco: Qalb al-Tawr (El Corazón de Tauro, situada en el ojo de la figura del toro), Qalb al-Asad (El Corazón de Leo, en el pecho del león) y Qalb al- 'Aqrab (El Corazón de Escorpio, en el tórax del escorpión); en la constelación boreal de Andrómeda, hay una cuarta estrella-corazón, Qalb al-Hūt (El Corazón del Pez) que, sin embargo, no tuvo una significación astrológica tan importante. Este artículo ilustra las características astrológicas de una estrella-corazón, su asociación con el concepto astrológico «cortador» que las convertía en especialmente dañinas en los horóscopos, así como su relación con bābanī, un término de origen persa.
\end{abstract}

Palabras clave: constelaciones; efectos de las estrellas; toponimia estelar; textos astrológicos árabes medievales.

Abstract: Medieval astrologers writing in Arabic used the term "heart-stars" to refer to three unusually bright stars that appear in the zodiac circle. They are Qalb al-Thawr (the Heart of Taurus, which appears as the eye of the bull), Qalb al-Asad (the Heart of Leo, which is in the lion's chest) and Qalb al-'Aqrab (the Heart of Scorpio, which appears in the thorax of the scorpion). In the northern constellation of Andromeda there is a bright star called Qalb al-Hüt (the Heart of the Fish), but its astrological significance was not so great. This paper illustrates how these astrologers attributed an evil influence to the three heart-stars on the zodiac circle. According to them, the heart-stars had an affinity with the planet Mars, which was known to have maleficent powers. Due to this connection, the heart-stars could block the motion of any heavenly body on its way around the circle of the zodiac. This meant that the heart-stars had a harmful effect on human affairs. In a prediction on the length of a human life, they were used to determine the date of death. In some astrological texts, the heart-stars were distinguished with a Persian adjective: the biyabāniyya stars.

Keywords: constellations; effects of the stars; star names; medieval Arabic astrological texts.

\section{SUMARIO}

1. Introducción.- 2. Fragmentos.- 2.1. Ibn Abī-l-Riŷāl.- 2.2. Ibn Abī-l-Riŷāl.2.3. Kūšyār ibn Labbān.- 2.4. Ibn Hibintā.- 2.5. Ibn 'Azzūz.-- 2.6. Ibn al-Bannā' .2.7. Compilador anónimo de Ibn Isḥāq.- 3. Comentario.- 4. Conclusiones.- 5. Bibliografía citada.

Citation / Cómo citar este artículo: Díaz-Fajardo, Montse (2019), Estrella-corazón, estrella-cortador: una interpretación nueva del concepto de estrella-bābanī, "Anuario de Estudios Medievales" 49/2, pp. 509-531. https://doi. org/10.3989/aem.2019.49.2.05

Copyright: (C) 2019 CSIC. Este es un artículo de acceso abierto distribuido bajo los términos de la licencia de uso y distribución Creative Commons Reconocimiento 4.0 Internacional (CC BY 4.0). 


\section{INTRODUCCIÓN}

En la terminología astrológica árabe, un número de voces provienen del persa. La mayoría de ellas representan conceptos astrológicos y, algunas, conceptos astronómicos. A modo de ejemplo, citamos los vocablos:

- $\hat{y} \bar{a} r$ bujtār ${ }^{1}$ : el planeta que gobierna el término $(h a d d)^{2}$ al que ha llegado la prorrogación ${ }^{3}$ del grado del ascendente ${ }^{4}$.

- $\hat{y}$ awzahar ${ }^{5}$ los nodos lunares.

- kadjuda $h^{6}$ : el planeta que gobierna sobre una de las cinco haylây, es decir, sobre el Sol, la Luna, el grado del ascendente, el sahm de la fortuna ${ }^{7}$ y el grado de la conjunción y de la oposición del Sol y la Luna. Es indicativo de los años de vida.

$-n \bar{\imath} m \bar{u} d \bar{a} r^{8}:$ método para verificar el grado del ascendente en un natalicio.

A pesar de incorporarse en el léxico astrológico árabe desde antiguo, ciertos vocablos persas no consiguieron fijar su forma, tal es el caso de $\hat{y} \bar{a} r$ bujtār, escrito también y yān bajtār y ŷān bajtān; un mayor número de variantes presenta nīmūdār tales como naymūdār, namūdār, namū $\underline{d} \bar{r} r$ y namū $\underline{d} a r$.

Incluso, en ocasiones, algunos vocablos propiciaron equívocos entre los usuarios en lengua árabe. Así, los traductores de Alfonso $\mathrm{X}$ de textos científicos del árabe al castellano, transliteraron al-ŷār bujtār con una grafía semejante $^{9}$ : algebuctar/agebuctar, pero, en otro pasaje, lo transliteraron con una grafía en la que el original es irreconocible: aliernistar, posiblemente

${ }^{1}$ Al-Juwārizmī, Mafātīh al- ‘ulūm, parte 6 - capítulo 3, véase Fajr al-Dīn 1991, p. 203; DíazFajardo 2011, p. 340.

${ }^{2}$ Véase la explicación de este concepto astrológico en la nota 66 y en el texto al que se refiere la nota.

${ }^{3}$ Una prorrogación o progresión en el círculo de la eclíptica (el círculo del zodiaco) es el avance aparente que el astrólogo daba a un cuerpo celeste para situarlo en otro punto del zodiaco en el que observaba los elementos celestes influyentes sobre el consultante, que le ayudaban a establecer el pronóstico astrológico.

${ }^{4} \mathrm{El}$ ascendente es el grado o punto de intersección entre la eclíptica y el horizonte oriental en un tiempo y lugar geográfico determinados. Dicho grado es el inicio de la casa I a partir del cual se delimitan el resto de las casas celestes para configurar un horóscopo.

${ }^{5}$ Al-Juwārizmī, Mafātīh al- 'ulūm, parte 6 - capítulo 2, véase Fajr al-Dīn 1991, p. 198.

${ }^{6}$ Al-Juwārizmī, Mafātīh al- 'ulūm, parte 6 - capítulo 3, véase Fajr al-Dīn 1991, p. 203.

${ }^{7}$ Un sahm es una posición en el círculo de la eclíptica calculada con la longitud $(\lambda)$ de tres cuerpos celestes (dos planetas, generalmente, y el ascendente). El sahm de la fortuna es igual a: ( $\lambda$ ascendente $+\lambda$ luna) $-\lambda$ sol. Al-Bīrūnī: en Ramsay-Wright 1934,pp. 279-295

${ }^{8}$ Díaz-Fajardo 2016, p. 130 nota 5.

${ }^{9}$ Díaz-Fajardo 2011, pp. 341-342, 367. 
porque el manuscrito que utilizaron presentaba una letra dudosa. Este dato ha contribuido a aumentar nuestro conocimiento sobre el trabajo de los traductores alfonsíes y su organización: es probable que tradujeran independientemente, distribuyendo los distintos capítulos del libro en cuestión entre los componentes del equipo de traducción. Esto, junto a que no se llevase a cabo una revisión conjunta posterior, explicaría las dos transliteraciones tan distantes que no pudieron identificar como pertenecientes a una misma palabra.

Hay un término de igual valor para los investigadores modernos ya que ha resultado controvertido en su contenido y uso. Se trata de biyabāniyya, al que está dedicado este estudio.

En los manuscritos medievales escritos en lengua árabe, el adjetivo $\underline{t a} \bar{a} b i t a$, cuando determina el sustantivo astros (kawākib), indica oposición mutua entre planetas (astros móviles, kawākib sayyāra) y estrellas (astros fijos, kawākib tāabita), tal y como ilustra la descripción del lingüista al-Juwārizmī (hacia 975):

Los astros móviles (al-kawākib al-sayyāra) son Saturno, Júpiter, Marte, el Sol, Venus, Mercurio y la Luna (...) Los astros fijos (al-kawākib al-țābita) son todos los astros que están en el cielo, excepto los siete [planetas o astros] móviles anteriores; se les denominó [astros o estrellas] fijas porque mantienen sus distancias de forma sistemática sin que se muevan extendiéndose [entre ellas] (...) Las estrellas fijas se hallan en cuarenta y cinco constelaciones ${ }^{10}$. De ellas, doce se encuentran en el centro del firmamento, son las constelaciones de los doce signos zodiacales: Aries, Tauro, Géminis, Cáncer, Leo, Virgo, Libra, Escorpio, Sagitario, Capricornio, Acuario y Piscis (...), diecinueve constelaciones son boreales (...) y catorce constelaciones son meridionales ${ }^{11}$.

En ocasiones, además de tābita, para designar las estrellas se emplea un adjetivo de procedencia no árabe: biyabān̄ (según algunas fuentes $b \bar{a} b a n \bar{\imath}$, bābān̄i) y su plural biyabāniyya (o las variantes biyābāniyya, bayabāniyya, y bābaniyya, bābāniyya).

En base a al-Mawālīd (Real Biblioteca del Monasterio, San Lorenzo de El Escorial, ms. 939, f. 32r-v) versión árabe realizada por Sa‘īd ibn Jurāsānjurra (hacia 747 y 754) de un escrito persa atribuido al mítico Zarādušt,

\footnotetext{
${ }^{10}$ Cuarenta y ocho constelaciones según el Almagesto (libro VII - capítulo 5 y VIII-1) de Ptolomeo. Toomer 1984, pp. 341-399.

${ }^{11}$ Al-Juwārizmī, Mafātīḥ al- 'ulūm, parte 6 - capítulo 1, véase Fajr al-Dīn 1991, pp. 193-194.
} 
Paul Kunitzsch ${ }^{12}$ constata que biyabāniyya se emplea como equivalente de $\underline{t} a \overline{b i t a}$, y denota el conjunto de las estrellas. Según Kunitzsch ${ }^{13}$, este significado es también sugerido por la etimología de biyabāniyya procedente del sustantivo pahlavi (persa sasánida) $a$-wiyābān- $\bar{g} g$ que deriva, a su vez, de la voz corriente griega para estrella.

Sin embargo, el astrónomo al-Bīrūn̄̄i ${ }^{14}$ (Juwārazm 973 - Gazna 1048) refiere que, en lengua persa, las estrellas se llamaron biyabāniyya porque orientan en los desiertos; Robert Ramsay-Wright, traductor de al-Bīrūn̄i, vierte biyabāniyya por "estrellas del desierto". Siguiendo esta línea, David Pingree ${ }^{15}$ considera que biyabāniyya es un gentilicio aplicable a una zona geográfica, "del desierto", y originado a partir del pahlavi wiyābān "desierto".

Podríamos hablar de una etimología científica (en correspondencia con el árabe țābita) y de una etimología popular (en analogía con desierto), pero, quizá, es interesante remarcar que biyabāniyya, en el primer caso (Zarādušt) aparece en una traducción de una fuente persa, y en el segundo caso (al-Bīrūnī) se le reconoce un origen persa.

El presente artículo propone que, en algunos textos no vinculados directamente con originales persas y creados alejados en el tiempo de la influencia cultural persa, el vocablo biyabāniyya evolucionó hacia otras interpretaciones.

Para ello, la metodología se ha basado en la observación y conceptualización de biyabāniyya según se ha encontrado en un grupo de textos de contenido astrológico, reveladores para nuestro propósito porque nos permiten distinguir el uso particular de dicho vocablo.

Los textos son fragmentos breves de fuentes árabes relevantes de los siglos X al XIV, en su mayoría astrólogos occidentales magrebíes. Algunas de ellas son manuales astrológicos (Ibn Abī-l-Riŷāl y Kūšyār ibn Labbān), zīŷy (el compilador anónimo de Ibn Isḥāq) y composiciones sobre un tema astrológico (Ibn al-Bannā') de gran popularidad en su tiempo. De otros manuales astrológicos utilizados como los de Ibn Hibintāe Ibn 'Azzūz, hemos empezado recientemente a conocer su influencia en el occidente islámico.

${ }^{12}$ Kunitzsch 1993a, pp. 241-249.

${ }^{13}$ Kunitzsch 1981, p. 265; 1993, p. 102; 1993a, pp. 244-245.

${ }^{14}$ Ramsay-Wright 1934, p. 46.

${ }^{15}$ Pingree 1989, p. 233.

${ }^{16}$ Un $z \bar{l} \hat{y}$ es un escrito compuesto de tablas con datos astronómicos y astrológicos, y sus instrucciones o cánones. La composición del compilador anónimo consta, en su mayor parte, de tablas de Ibn Ishāa (Túnez, hacia 1193-1222) y de unos pocos autores andalusíes; el compilador completó el conjunto de tablas con instrucciones de fuentes andalusíes diversas. Hacia 1260, ya se habían añadido algunas instrucciones a las tablas de Ibn Isḥāq que, en un principio, estaban disponibles sin ellas. Mestres 1996, pp. 385, 389-392. 
Presentados en la sección 2, los fragmentos 2.1 (Ibn Abī-l-Riŷāl), 2.4 (Ibn Hibintā), 2.5 (Ibn 'Azzūz) y 2.7 (compilador anónimo de Ibn Isḥāq) ilustran el término biyabāniyya.

Los fragmentos 2.5 (Ibn 'Azzūz) y 2.6 (Ibn al-Bannā') tienen especial interés porque aunque son fragmentos paralelos, el primero dice bābaniyya mientras que el de Ibn al-Bannā' copia țābita.

Los fragmentos 2.4 (Ibn Hibintā) y 2.5 (Ibn 'Azzūz) permiten obtener una idea de la interpretación nueva de biyabāniyya. En ellos, el término biyabāniyya se dispone de forma que su sentido se acerca a unas estrellas concretas llamadas qulūb (corazones). El adjetivo corazón pone en relación el nombre de la estrella con el color rojizo o con la parte que la estrella ocupa en su constelación; es sabido que, desde la Antigüedad, grupos de estrellas aparentemente próximas entre sí fueron imaginados con forma de figura humana, de animal o de objeto.

El fragmento 2.2 (Ibn Abī-l-Riŷāl) relaciona las estrellas-qulūb (corazones) con las estrellas-qawāti ‘ (cortantes, cortadores). El fragmento 2.3 (Kūšyār ibn Labbān) delimita el significado de cortador. Los cortadores, en general, son cuerpos celestes que causan perjuicio en el estado de una persona o cosa; un cortador era un componente en un horóscopo, así como en una prorrogación.

El objetivo de nuestro trabajo es dar respuesta, en el comentario de la sección 3, a los tres interrogantes planteados por los elementos anteriores: ¿cuáles eran las estrellas-corazones?, ¿por qué eran representativas las estrellas-corazones?, ¿qué uso tiene biyabāniyya en los fragmentos seleccionados? y demostrar que el término de la astrología persa, biyabāniyya, tomó una nueva significación (distinta de la referida por Kunitzsch, Ramsay-Wright [al-Bīrūnī] y Pingree) ya que se le dotó de un concepto astrológico específico equiparando las estrellas denominadas biyabāniyya con las estrellas-corazones y las estrellas-cortadores. Esto es significativo desde el punto de vista histórico, pues muestra la evolución de los tecnicismos astrológicos en textos elaborados y/o copiados en el norte de África, lo que contribuye a conformar las características de la astrología desarrollada en esa zona del occidente islámico.

\section{FRAGMENTOS}

\subsection{Ibn Abī-l-Riŷāl}

Ibn Abī-l-Riŷāl (floreció Túnez hacia 965-1050), Kitāb al-bāri` fì ahkām al-nuŷūm, parte III, p. 148. 


$$
\begin{aligned}
& \text { و إذا كان على درجة مركزه كوكب باباني يماز جمز اج المشتري و عطارد و أحدهما صاحب } \\
& \text { الطالع و هما ينظر ان إلى الباباني نظر ا محمودا من مكان جيّد غير منحوس دلَ على أنَّ المولود أو بردي }
\end{aligned}
$$

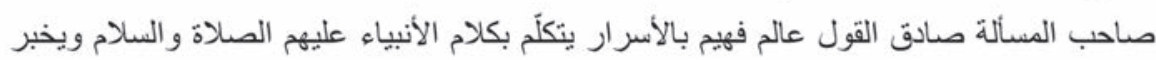

$$
\begin{aligned}
& \text { بالأحو ال المكتومة. }
\end{aligned}
$$

Cuando, en el grado de su centro [del centro de una casa celeste], hay una estrella $b \bar{a} b \bar{a} n \bar{\imath}$ constituida con el temperamento de Júpiter y Mercurio, y uno de estos planetas es señor del ascendente, y los dos planetas están en aspecto con la $b \bar{a} b \bar{a} n \bar{\imath}$ favorablemente y desde una posición buena sin elementos nefastos, señala que el nacido o el consultante es de palabra certera, descubridor y conocedor de secretos, capaz de hablar con las palabras de los profetas, sobre ellos sea la bendición y la paz, y de hacer saber situaciones ocultas.

\subsection{Ibn Abī-l-Riŷāl}

Ibn Abī-1-Riŷāl (fl. Túnez hacia 965-1050), Kitāb al-bāri ‘ fì aḥkām al-nuŷum, parte IV, p. 230.

$$
\begin{aligned}
& \text { فمتى انتهى إلى جسد نحس أو مقابلته أو تربيعه حكمت بالنكبة والقطع إن لم ينظر سعد بجسد } \\
& \text { أو شعاع و[لا] سنيما إن كان التسيير في حدود النحوس و أواخر البروج والكو اكب الثابتة القلوب وما } \\
& \text { شاكلها وهي التي في طبانع النحوس تقتل وتأتي بالنكبات العظيمة إذا لم ينظر سعد. }
\end{aligned}
$$

Cuando [la prorrogación de un elemento celeste] finaliza en un cuerpo maléfico o en oposición y cuadratura con un maléfico, juzga desgracia y corte (qat $\left.t^{\circ}\right)$ en caso de que un planeta benéfico, en cuerpo o rayo, no esté aspectado; sobre todo si la prorrogación se encuentra en los términos de los maléficos, los grados finales de los signos, las estrellas-corazones (al-kawākib al-țābita al-qulūb) y otros semejantes pues son los que, con la naturaleza de los maléficos, matan y traen grandes desgracias si un planeta benéfico no está aspectado.

\subsection{Kūšyār ibn Labbān}

Kūšyār ibn Labbān (Guilán, hacia fines del siglo X, principios del XI), al-Madjal fī șinā'at aḥkām al-nuŷūm, edición de Yano 1997, pp. 18-19. 


\section{الكو اكب الثابتة كثيرة (...) ومنها قو اطع على طبيعة النحوس ومز اجهنَ يقطعن على الأعمار ويفسن الأحوال والأمور إذا انتهى التسيير من ابتدائها إلى هذه الكواكب.}

Las estrellas fijas (al-kawākib al-tāabita) son muchas (...) Algunas de ellas son cortantes ( $q a w a \bar{a} t i^{\circ}$ ) con la naturaleza de los maléficos; el temperamento de esas estrellas detiene la vida y echa a perder circunstancias y asuntos cuando la prorrogación [de un elemento celeste] llega, desde su inicio, a esas estrellas.

\subsection{Ibn Hibintā}

Ibn Hibintā (fl. Iraq hacia 941), al-Mugnī fì aḥkām al-nuŷūm, p. 279.

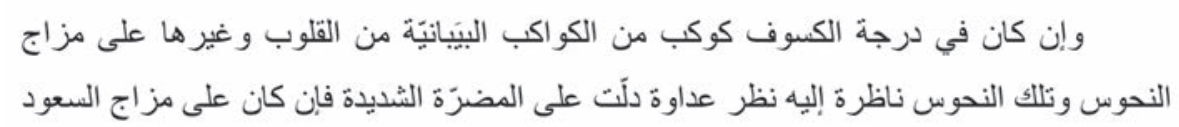

وهي ناظرة إليه كان الثرّ أقلّ.

$\mathrm{Si}$, en el grado del eclipse, se encuentra una de las estrellas biyabāniyya que sea una de las corazones o de otras con el temperamento de los maléficos, y esas maléficas están aspectadas con el eclipse de forma nefasta, señalan daño intenso; si poseen el temperamento de los benéficos y están aspectadas con el eclipse, el daño es menor.

\subsection{Ibn 'Azzūz}

Ibn 'Azzūz (Constantina, m. 1354), Kitāb al-fuṣūl fì ŷam'al-uṣūl, f.

$121 v$.

$$
\begin{aligned}
& \text { فمنى مرّت درجة تحت التسييرات بأحد الكواكب الثابتة التي هي قلوب البروج البابنيّة أو }
\end{aligned}
$$

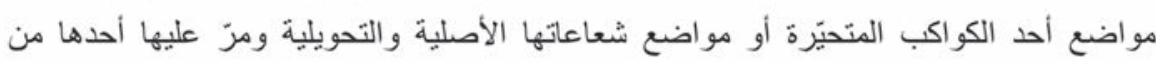

$$
\begin{aligned}
& \text { المناظرة الأربع التي هي التسديس و التثليث و التربيع و المقابلة أتت بأنو اع جو اهر ها و أصناف دلالتها } \\
& \text { بقدر ما كانت ممازجتها و المخالصة لها. }
\end{aligned}
$$

Cuando un grado, mediante las prorrogaciones, pase por una de las estrellas fijas (al-kawākib al-țābita) que sea de las corazones de los signos, las bābaniyya, por las posiciones de un planeta o por las posiciones de los rayos de los planetas, [ya fueran posicio- 
nes de horóscopos] radicales y aniversarios, y uno de los cuatro aspectos (el sextil [es decir, cuando entre dos puntos celestes hay una distancia de $60^{\circ}$, el trino $\left[120^{\circ}\right]$, la cuadratura $\left[90^{\circ}\right]$ y la oposición $\left.\left[180^{\circ}\right]\right)$ pase por el grado, señalarán el tipo de naturaleza e indicación que posean según cuál sea su mezcla y su pureza.

\subsection{Ibn al-Bannā'}

Ibn al-Bannā' (Marrakech, 1256-1321), [al-Kalām 'alà l-tasyīrāt wa-mațāriḥ al-šu 'ā ‘ât ], edición de Djebbār, Aballāgh 2001, p. 160.

$$
\begin{aligned}
& \text { فمنى مرّت درجات إحدى التسييرات بأحد الكواكب الثابتة التي هي قلوب البروج الثابتة أو } \\
& \text { بمواضع أحد الكواكب المتحتيرة أو بمواضع شعاعها من بيوتها أو نظر أحدها من بيته وهو } \\
& \text { التسديس و التنليث و التربيع و المقارنة و المقابلة و غير ذلك من أوصاف دلالتها بقدر ما كانت مازجتها } \\
& \text { فإن كانت سعودا أعطت السعادة (...) وإن كانت نحوسا أخبرت بأنو اع النكبات. }
\end{aligned}
$$

Cuando los grados de una de las prorrogaciones pasen por una de las estrellas fijas (al-kawākib al-țābita) que sea de las corazones de los signos fijos (al-burūŷy al-țābita $)^{17}$, por las posiciones de un planeta, por las posiciones de los rayos de los planetas desde sus domicilios, y uno de los planetas, desde su domicilio, está en aspecto (es decir en sextil, trino, cuadratura, conjunción u oposición), o por cualquier otra clase de señales, según cuál sea su mezcla, darán fortuna si fueran favorables (...) e informarán de todo tipo de desgracias si fueran desfavorables.

\subsection{Compilador anónimo de Ibn Isḥāq}

Compilador anónimo (Túnez, hacia 1281) de Ibn Isḥāq, [Z̄îy de Ibn Ishạa , edición de Mestres 1999, capítulo 43 de los cánones.

\footnotetext{
${ }^{17}$ Los signos fijos son Tauro, Leo, Escorpio y Acuario. De acuerdo con Ptolomeo, la acción de un signo fijo es como sigue: cuando el sol está en los signos fijos, la humedad, el calor, la sequedad y el frío de las estaciones (que comenzaron en los signos precedentes) nos afecta con más intensidad porque ya estamos habituados al tiempo y es entonces cuando somos más sensibles a su fuerza. Según Ptolomeo y Abū Ma‘šar, el resto de los signos se clasifican en tropicales (equinocciales: Aries y Libra, y solsticiales: Cáncer y Capricornio), y bicorporales (Géminis, Virgo, Sagitario y Piscis). Robbins 1980, pp. 65-69; Burnett, Yamamoto, Yano 1994, pp. 14-25.
} 


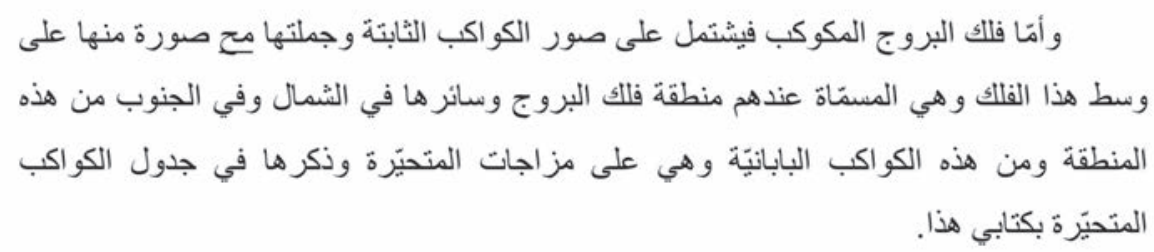

La esfera estrellada de los signos contiene las constelaciones de las estrellas fijas (al-kawākib al-tāabita), en total son 48 constelaciones, de ellas unas están situadas en el centro de esa esfera, que es denominada por ellos la zona de la esfera de los signos zodiacales, y el resto de las constelaciones se encuentran al norte y al sur de esa zona; entre estas estrellas están las bābāniyya que poseen los temperamentos de los planetas mencionados en la tabla de los planetas en este mi libro.

\section{COMENTARIO}

Sobre el número de estrellas-corazones, las listas de estrellas en los manuales astrológicos, las tablas de estrellas en los $z \bar{\imath} \hat{y}$, y los libros de temática estelar con un carácter astrológico (como el Del saber de astronomía ${ }^{18}$ mencionan generalmente dos estrellas con la denominación corazón (qalb, plural qulūb): El Corazón de Leo y El Corazón de Escorpio. El apelativo corazón indica que, a semejanza del órgano que representa, la estrella está situada en el tórax de la figura formada por la constelación ${ }^{19}$.

El listado siguiente presenta el nombre, las coordenadas, el color y la magnitud de las estrellas-corazones anteriore ${ }^{20}$ :

1. El Corazón de Leo, Qalb al-Asad.

- Nombre alternativo: Régulo (al-Malik̄̄, al-Mulūkī), El Corazón $(\text { al-Qalb })^{21}$.

- Nombre técnico: $\alpha$ Leonis.

- Coordenadas: longitud Leo 2;30 y latitud norte $0 ; 10^{022}$.

\footnotetext{
${ }^{18}$ Rico y Sinobas 1863-1867, vol. I, pp. 63-64.

${ }^{19}$ Véase las imágenes (no 26 y 29) de ambas constelaciones en al-Ṣūfî (Schjellerup 1874).

${ }^{20}$ Se han tomado las coordenadas del Almagesto de Ptolomeo (Toomer 1984) y, en general, el resto de datos de al-Șūfī (Schjellerup 1874); en nota, se especifican otros autores.

${ }^{21}$ La segunda denominación la da Ibn 'Āṣim, véase Forcada 1993, p. 250.

${ }^{22}$ Ptolomeo (Toomer 1984, p. 367).
} 
- Color: blanco y nítido ${ }^{23}$.

- Magnitud: $1^{24}$.

2. El Corazón de Escorpio, Qalb al- 'Aqrab.

- Nombre alternativo: no tiene ${ }^{25}$.

- Nombre técnico: $\alpha$ Scorpii.

- Coordenadas: longitud Escorpio $12 ; 40^{\circ}$ y latitud sur $4^{026}$.

- Color: rojizo resplandeciente ${ }^{27}$.

- Magnitud: $2^{28}$.

La aplicación del adjetivo corazón fue desigual. Así, en su catálogo de estrellas, el astrónomo al-Ṣūfī (903 - Shiraz 986) refiere, junto a El Corazón de Leo y El Corazón de Escorpio, una tercera estrella-corazón: El Corazón del Pez que, en una representación, corresponde al corazón de un pez $^{29}$ dibujado sobre la cintura de Andrómeda constelación boreal en forma de mujer; en otra representación, dicha estrella se encuentra al este en la cintura encadenada de Andrómeda (en árabe La Mujer Encadenada: alMar'a al-Musalsala) $)^{30}$.

Además de en al-Ṣūfī, El Corazón del Pez aparece con el nombre corazón, el menos usual, en la composición sobre ortos y ocasos estelares de Ibn 'Āṣim ${ }^{31}$ (fl. Córdoba, m. 1013) y en la lista de estrellas de un manual para construir un astrolabio atribuido a Ibn al-Zarqālluh (fl. Toledo y Córdoba, m. 1100$)^{32}$. Los datos de esta estrella son:

3. El Corazón del Pez, Qalb al-Hūt.

- Nombre alternativo: El Vientre del Pez (Bațn al-Hūt), El Pez (al-Samaka), La Cuerda de Pozo (al-Rišā'), La Cadera de la

\footnotetext{
${ }^{23}$ De acuerdo con Zarādušt, al-Mawālīd, f. 24v.

${ }^{24}$ Al-Ṣūfī (Schjellerup 1874, p. 157); Kūšyār Ibn Labbān (Yano 1997, pp. 22-23).

${ }^{25}$ El Corazón de Escorpio es Antares en griego (Robbins 1980, p. 51).

${ }^{26}$ Ptolomeo (Toomer 1984, p. 372).

${ }^{27}$ Al-Ṣūî̀ (Schjellerup 1874, pp. 172, 174); al-Bīrūnī (Ramsay-Wright 1934, p. 84).

${ }^{28}$ Al-Șūfĩ (Schjellerup 1874, p. 174); Kūšyār Ibn Labbān (Yano 1997, pp. 22-23).

${ }^{29}$ Este pez no tiene que ver con la constelación zodiacal de Piscis sino que es parte del dibujo de Andrómeda, véase al-Bīrūnī en: Ramsay-Wright 1934,pp. 79, 85.

${ }^{30}$ En las distintas figuras de Andrómeda, la situación del pez y de la estrella El Corazón del Pez varía ligeramente, véase Schjellerup 1874, pp. 120-121, figuras 19 y 19a; Rico y Sinobas 1863-1867, figura contigua a la p. 54.

${ }^{31}$ Forcada 1993, p. 203.

${ }^{32}$ Kunitzsch 1980, p. 199.
} 
Mujer (Wark al-Mar'a), El Costado de la [Mujer] Encadenada $(\hat{Y} \text { anb al-Musalsala })^{33}$.

- Nombre técnico: $\beta$ Andromedae.

- Coordenadas: longitud Aries 3;50 y latitud norte 26;20 $0^{\circ 34}$.

- Color: brillante ${ }^{35}$.

- Magnitud: $2.3^{36}$.

Como se ha referido, entre los tratados medievales que proporcionan información sobre las estrellas hay que tener en cuenta los libros de tradición árabe sobre astro-meteorología que consideran la salida y la puesta de las estrellas $^{37}$ indicadores de las condiciones climáticas. En concreto, el compuesto por Ibn 'Āṣim nombra las estrellas-corazones siguientes: El Corazón de Leo (Qalb al-Asad), El Corazón de Escorpio (Qalb al- 'Aqrab), El Corazón del Pez (Qalb al-Hüt) y El Corazón de Tauro (Qalb al-Tawr) ${ }^{38}$.

Vemos que Ibn ‘Āṣim añade una cuarta estrella-corazón: El Corazón de Tauro.

En la constelación de Tauro, Ibn 'Azzūz (citando, probablemente, a Ibn Rị̣̂ān, El Cairo, 998-1061/o 1069) menciona estrellas en la espaldilla, la cabeza y el cuerno del toro, y distingue dos estrellas con nombre propio: las Pléyades y Aldebarán, pero no nombra estrellas en el corazón de la figura ${ }^{39}$.

Una de las estrellas más relevantes de Tauro es el luminar Aldebarán, también llamado en árabe El Ojo de Tauro por caer bien en la cabeza (según Ibn 'Azzūz que transmite a Ibn Riḍwān) bien en el ojo meridional (según alȘūfī) del toro ${ }^{40}$.

\footnotetext{
${ }_{33}^{3}$ Al-Ṣūīi (Schjellerup 1874, pp. 116-117, 120); Ibn 'Āṣim (Forcada 1993, pp. 74, 203); al-Bīrūnī (Ramsay-Wright 1934, p. 85); los libros Del saber de astronomía (Rico y Sinobas 1863-1867, pp. 53, 131); Ibn al-Raqqām (fl. Túnez y Granada, 1245-1315) (Parra 2012, p. 35); Kunitzsch 1980, p. 199; Kunitzsch 1964, p. 399.

${ }^{34}$ Ptolomeo (Toomer 1984, p. 359).

${ }^{35}$ Al-Șūfī (Schjellerup 1874, p. 196); Ibn ‘Āṣim (Forcada 1993, p. 203).

${ }^{36} \mathrm{Al}$-Ṣūī (Schjellerup 1874, p. 121).

${ }^{37}$ El llamado naw', el ocaso acrónico de una estrella (última estrella que cruza el horizonte occidental justo antes de la salida del sol), y el orto helíaco de su estrella opuesta conocida por raqīb (la última estrella que cruza el horizonte oriental justo antes de la salida del sol), ambos sucediendo a un tiempo. Al-Șūfī (Schjellerup 1874, p. 135 nota 4); Forcada 1993, pp. 19-20.

${ }^{38}$ Ibn 'Āṣim (Forcada 1993, pp. 249-250).

39 Ibn 'Azzūz, Kitāb al-fușūl fì ŷam' al-ușūl, f. 136r-v; Ibn Rị̣̂ān, al-Arba' Maqālāt [traducción comentada del Tetrabiblos de Ptolomeo], f. 24r; véase también al-Șūfì (Schjellerup 1874, pp. 129-140).

${ }^{40} \mathrm{Ibn}$ 'Azzūz, Kitāb al-fușūl fì ŷam ' al-uṣūl,f. 136v; Ibn Riḍwān, al-Arba' Maqāāāt, f. 24r; al-Șūfî (Schjellerup 1874, pp. 130-131).
} 
La identificación de El Corazón de Tauro con Aldebarán está documentada en al-Marzūqī (fl. Persia, 971-1030) ${ }^{41}$, y en la lista de estrellas de las tablas alfonsíes ${ }^{42}$ en la que se lee Aldebaran id est oculus vel cor Tauri (Aldebarán es el ojo o el corazón de Tauro).

En este caso, la denominación corazón parece atribuirse no a su posición en la figura sino al color rojizo de la estrella. Los datos de Aldebarán son:

4. El Corazón de Tauro, Qalb al-Tawr.

- Nombre alternativo: Aldebarán (al-Dabarān), El Ojo de Tauro ('Ayn al-Tawr), al-Fan̄̄q (El Camello Grande) ${ }^{43}$, La Siguiente de las Pléyades ${ }^{44}$, El que arrea $(H \bar{a} d \bar{\imath})$ a La Estrella ${ }^{45}$, al-Mî̀ $d a h^{46}$.

- Nombre técnico: $\alpha$ Tauri.

- Coordenadas: longitud Tauro $12 ; 40^{\circ}$ y latitud sur $5 ; 10^{047}$.

- Color: rojizo resplandeciente ${ }^{48}$.

- Magnitud: $1^{49}$.

Además de su denominación común, la segunda característica que une a las estrellas-corazones es que son mansiones lunares: Aldebarán [El Corazón de Tauro] es la cuarta mansión de la luna, El Corazón de Leo forma parte según distintas tradiciones, bien de la mansión décima bien de la duodécima, El Corazón de Escorpio es la decimo octava mansión de la luna, y El Vientre del Pez [El Corazón del Pez] es la vigésimo octava ${ }^{50}$.

${ }^{41}$ Forcada 1993, p. 78.

${ }^{42}$ Kunitzsch 1986, pp. 90, 97 nota 23.

${ }^{43}$ Al-Fañ̄q lo mencionan al-Bīrūnī (Ramsay-Wright 1934, pp. 77, 80), Del Saber de Astronomía (Rico y Sinobas 1863-1867, p. 133) y al-Șūfī (Schjellerup 1874, p. 135).

${ }^{44}$ Las Pléyades es la tercera mansión lunar y Aldebarán [El Corazón de Tauro], la cuarta Al-Bīrūnī (Ramsay-Wright 1934, p. 82) refiere que Aldebarán era llamada La Siguiente de La Estrella, donde La Siguiente ( $t a \bar{a} b i^{\circ}$ o $\left.t \bar{a} \bar{l} \bar{\imath}\right)$ es Aldebarán, y La Estrella es las Pléyades; la misma explicación se encuentra en al-Ṣūfî (Schjellerup 1874,pp. 131, 134-135). García Campos (1953, p. 38) apunta que $a l$-dabrā' significa "los que nos suceden", y de ésta al-dabarān: "los que van detrás, los zagueros"; este sentido se da en los libros Del saber de astronomía (Rico y Sinobas 1863-1867, pp. 132-133), al-Șūfì (Schjellerup 1874, p. 135) e Ibn 'Āșim (Forcada 1993, p. 216).

${ }^{45}$ Al-Șūfī (Schjellerup 1874, p. 135); Ibn 'Āṣim (Forcada 1993, p. 216).

${ }^{46}$ Al-Șūfì (Schjellerup 1874, p. 135); Forcada 1993, p. 78. Esta denominación parece corresponderse con la transliteración del castellano antiguo Mistach de las Pléyades (los libros Del saber de astronomía: Rico y Sinobas 1863-1867, p. 133).

${ }^{47}$ Ptolomeo (Toomer 1984, p. 362).

${ }^{48}$ Al-Șūfī (Schjellerup 1874, p. 138); al-Bīrūnī (Ramsay-Wright 1934, p. 82). De acuerdo con Ptolomeo (Robbins 1980, p. 47), El Corazón de Tauro era llamada en griego La Antorcha lo que da una idea de su resplandor y tono.

${ }^{49}$ Al-Ṣūfī (Schjellerup 1874, p. 138); Kūšyār Ibn Labbān (Yano 1997, pp. 20-21).

${ }^{50}$ En un ciclo lunar de 28 días, una mansión lunar es la estrella, la pareja de estrellas, el grupito de estrellas e incluso la ausencia de estrellas que hay cerca de la luna cada noche; por 
Las estrellas-corazones tuvieron relevancia en materias diferentes.

De los escritos de astro-meteorología y toponimia estelar se desprende que las estrellas-corazones:

a. Se transmitieron a la cultura popular:

- El Corazón de Tauro: según Ibn 'Āṣim y al-Șūfī, existía el dicho «es peor que La Siguiente de las Pléyades»; para al-Ṣūfī, podía aludir tanto a una persona como a la lluvia que, si caía durante el ocaso (en concreto, durante el naw') de Aldebarán, anunciaba un año de escasez. De acuerdo con al-Bīrūnī, traía mala suerte e infelicidad ${ }^{51}$.

- El Corazón de Leo: en oriente, fue apodada El Amuleto (alSarfa), por tanto era una estrella con connotaciones favorables $^{52}$.

- El Corazón del Pez: su salida marcaba el fin del frío y el mejor momento para que los ascetas recorriesen los caminos ${ }^{53}$.

b. Fueron indicios de un tiempo atmosférico, en general, extremo; su salida señalaba:

- El Corazón de Tauro: según Ibn 'Āṣim, un aumento del calor, viento cálido y aparición de moscas; de acuerdo con alBattānī (fl. Raqqa, m. 929), incendios y rayos ${ }^{54}$.

- El Corazón de Leo: según al-Battān̄̄5 , aire cálido estancado y epidemias.

- El Corazón de Escorpio: según Ibn 'Āṣim, frío y heladas que desaconsejaban el apareamiento de las camellas flacas; de acuerdo con al-Bīrūn̄̄ e Ibn 'Āṣim, El Corazón de Escorpio y Vega [ $\alpha$ Lyrae], cuyos ortos se producían a un tiempo, se apodaron al-Harrārān, es decir, los dos perros que gimen [a causa del frío $]^{56}$.

tanto, el número de mansiones lunares es 28. Sobre las mansiones de la luna, véase al-Bīrūnī (Ramsay-Wright 1934, pp. 81-87); Forcada 1993, pp. 20-23; Kunitzsch 1987, pp. 374-376; Comes 1990,pp. 100-103.

${ }^{51}$ Ibn 'Āṣim (Forcada 1993, p. 216); al-Ṣūfī (Schjellerup 1874, p. 136); al-Bīrūn̄̄ (RamsayWright 1934, p. 80).

${ }_{52}$ García Campos 1953,p. 64.

${ }^{53} \mathrm{Ibn}$ 'Āṣim (Forcada 1993,pp. 203, 204).

${ }^{54} \mathrm{Ibn}$ 'Āṣim (Forcada 1993, pp. 216-217); al-Battān̄̄, al-Arba' Maqālāt [resumen comentado del Tetrabiblos de Ptolomeo], f. 32r.

${ }^{55} \mathrm{Al}$-Battān̄̄, al-Arba' Maqālāt, f. 32r.

${ }^{56}$ Ibn 'Āṣim (Forcada 1993, pp. 250-251); al-Bīrūnī (Ramsay-Wright 1934, p. 79); al-Ṣūfī (Schjellerup 1874, p. 77). 
- El Corazón del Pez: según al-Battānīi ${ }^{57}$, las estrellas que tienen únicamente el temperamento de Venus [como es el caso de El Corazón del Pez, véase más adelante] señalan mucha humedad y lluvias.

Si nos fijamos en las composiciones astronómicas y astrológicas, alȘūfī ${ }^{58}$ explica que las tablas de estrellas recogen las estrellas más célebres y conocidas por todos. De las cinco estrellas que al-Ṣūî̀ menciona como ejemplo de célebres tres son las estrellas-corazones El Corazón de Tauro, El Corazón de Leo y El Corazón de Escorpio. Probablemente, por su nitidez, magnitud y visibilidad, esas estrellas-corazones aparecían invariablemente en las listas y tablas de estrellas de manuales astrológicos y zî̀y, catálogos estelares, y tablas cortas de estrellas para ser grabadas en una lámina de astrolabio ${ }^{59}$. Por lo que se refiere a El Corazón del Pez, su inclusión es inconstante y los manuales astrológicos no ofrecen particularidades sobre esta estrella quizá porque, respecto al resto de estrellas-corazones, presenta un factor divergente: su considerable latitud y su pertenencia a una constelación externa a la franja de los signos zodiacales.

Según la descripción astrológica que ofrece el Del saber de astro$n_{\text {nomía }}{ }^{60}$, las estrellas-corazones se identifican con la distinción y el honor, aunque El Corazón de Leo y El Corazón de Escorpio pueden apuntar también infortunio.

Pero los fragmentos de Ibn Abī-l-Riŷāl (sección 2.2) y Kūšyār Ibn Labbān (2.3) transmiten otra práctica que, probablemente, tenga su origen en el concepto de la astrología clásica «temperamento» (en árabe mizāŷy) por el que las cualidades (la acción: $f i^{`} l$, y la fuerza: $q u w w a$ ) de una estrella se fijan a través de un paralelismo con las cualidades de un planeta.

De acuerdo con Ptolomeo (Tetrabiblos, libro I, capítulo 9) ${ }^{61}$, el temperamento es la fuerza que la estrella posee de uno, dos, y en ocasiones tres planetas.

El calor, el frío, la humedad y la sequedad son los elementos que distinguen a los planetas. Según Ptolomeo (Tetrabiblos I, 4-5) ${ }^{62}$, el calor y la

\footnotetext{
${ }^{57}$ Al-Battān̄̄, al-Arba‘ Maqālāt, f. 32r.

${ }^{58}$ Schjellerup 1874, p. 29.

${ }^{59}$ Otros ejemplos de la presencia de las tres estrellas-corazones en: Vernet, Català 1965 , p. 45; Comes 1994, p. 106; Samsó 2000, pp. 516-521.

${ }^{60}$ Rico y Sinobas 1863-1867, p. 54 [El Corazón del Pez], p. 64 [El Corazón de Tauro], p. 70 [El Corazón de Leo], p. 76 [El Corazón de Escorpio]; la naturaleza astrológica de El Corazón del Pez no se describe tan solo se apunta que los hechos serán a semejanza de la representación de Andrómeda.

${ }^{61}$ Robbins 1980, pp. 46-59.

${ }^{62}$ Ibidem, pp. 34-39.
} 
humedad son humores fértiles y activos, mientras que el frío y la sequedad son destructivos y pasivos. Así, los planetas de naturaleza cálida y húmeda se consideran benéficos (la Luna: húmedo; cálido en menor grado. Venus: húmedo; cálido en menor grado. Júpiter: cálido; húmedo en menor grado), y aquellos que poseen una naturaleza fría y seca son maléficos (Marte: seco. Saturno: frío; seco en menor grado). Los planetas restantes son benéficos y maléficos (Mercurio: seco y húmedo. El Sol: cálido; seco en menor grado).

Esta tradición ptolemaica es la que se observa en numerosos autores árabes cuyas tablas o listas de estrellas especifican los planetas asociados con cierta estrella ${ }^{63}$.

Como se muestra a continuación, las tres estrellas-corazones de los signos zodiacales coinciden en una acción y fuerza maléficas por su afinidad con el planeta Marte ${ }^{64}$ :

- El Corazón de Tauro: temperamento de Marte.

- El Corazón de Leo: temperamento de Marte y Júpiter.

- El Corazón de Escorpio: temperamento de Marte y un poco de Júpiter.

- El Corazón del Pez: temperamento de Venus.

De los fragmentos de Ibn Abī-l-Riȳāl (2.2) y Kūšyār Ibn Labbān (2.3) se desprende que la simbología dañina de las estrellas-corazones se amplificó de dos formas:

- A través de la equiparación de las estrellas-corazones con los términos astrológicos de los planetas maléficos, Marte y Saturno, y con los grados finales de los signos.

Doroteo de Sidón refuerza esa percepción ${ }^{65}$ : cuando la Luna se encuentra en los grados últimos de un signo quiere decir que está bien en el término de Saturno o bien en el de Marte, y entre los términos situados al final de los signos ninguno es peor que los gobernados por esos dos planetas.

Los términos (en árabe hadd, plural hudūd) astrológicos son, en los signos zodiacales, segmentos de cantidad desigual bajo el gobierno de un

\footnotetext{
${ }^{63}$ Véase por ejemplo, la tabla de estrellas de Ibn al-Kammād (Goldstein, Chabás 1996, p. 321) o los listados de Kūšyār Ibn Labbān (Yano 1997, pp. 20-25) e Ibn Nawbajt (Labarta, Mestres 2005, pp. 15-19).

${ }^{64}$ Ptolomeo no distingue El Corazón del Pez sino que alude en conjunto a las estrellas de Andrómeda, véase Robbins 1980, p. 47 [El Corazón de Tauro],p. 49 [El Corazón de Leo], p. 51 [El Corazón de Escorpio], p. 57 [estrellas de Andrómeda].

${ }^{65}$ En su poema astrológico (V-5): Pingree 1976, p. 108 no. 8 texto árabe, p. 264 no. 8 traducción.
} 
planeta; la mayoría de los términos de los dos planetas maléficos están situados en los grados finales de los signos ${ }^{66}$.

- A través de la asociación de las estrellas-corazones con los conceptos astrológicos corte (qat $\left.t^{\circ}\right)$ y cortante, cortador ( $q \bar{a} t i^{\circ}$, plural qawāti $i^{\circ}$.

Esa cualidad se ratifica en el listado de estrellas de Kūšyār Ibn Labbān que presenta la singularidad de indicar las estrellas-cortadores, entre las que están los corazones de los signos: El Corazón de Tauro, El Corazón de Leo y El Corazón de Escorpio ${ }^{67}$.

¿En astrología, qué significa ser cortante o un cortador?

Puede tener un sentido propicio marcado por uno de los planetas asociados con la estrella, por ejemplo Ibn 'Azzūz (citando a Ibn Riḍ̂ān) refiere que las dos estrellas que están a los lados del Pesebre, llamadas Los Dos Burros $^{68}$, tienen el temperamento de Marte y el Sol. Estas estrellas son cortantes debido al dominio del calor y la sequedad y señalan la victoria y el triunfo ${ }^{69}$.

Pero en general, cortante es un elemento celeste de mal augurio que expresa un peligro. Se conservan horóscopos en los que un astrólogo identifica los cortadores celestes explicativos del escenario que, en la batalla de El Salado en 1340, condujo al sultán Abū-1-Hasan 'Alī (1331-1351) a la derro$\mathrm{ta}^{70}$. Hay textos que ilustran las prácticas religiosas preventivas que un imán aconsejaba a un consultante alterado después de saber que su astrólogo había

${ }^{66}$ Tal y como se observa en la lista siguiente de términos astrológicos: Aries $\Upsilon$ : desde $\Upsilon 20^{\circ}$ hasta $\Upsilon 25^{\circ}$ : término de Marte; desde $\Upsilon^{2} 5^{\circ}$ hasta $\Upsilon 30^{\circ}$ : término de Saturno. Tauro $\gamma$ : desde $\succ 22^{\circ}$ hasta $\succ 27^{\circ}$ : término de Saturno; desde $\succ 27^{\circ}$ hasta $\succ 30^{\circ}$ : término de Marte. Géminis II: desde II $17^{\circ}$ hasta II $24^{\circ}$ : término de Marte; desde II $24^{\circ}$ hasta II $30^{\circ}$ : término de Saturno. Cáncer $\sigma:$ desde $\sigma 0^{\circ}$ hasta $\sigma 7^{\circ}$ : término de Marte; desde $\sigma 26^{\circ}$ hasta $\sigma 30^{\circ}$ : término de Saturno. Leo $\Omega$ : desde $\delta 11^{\circ}$ hasta $\delta 18^{\circ}$ : término de Saturno; desde $\delta 24^{\circ}$ hasta $\delta 30^{\circ}$ : término de Marte. Virgo Ml: desde M $21^{\circ}$ hasta Ml2 $28^{\circ}$ : término de Marte; desde Ml $28^{\circ}$ hasta Ml $30^{\circ}$ : término de Saturno. Libra $\Omega$ : desde $\Omega 0^{\circ}$ hasta $\Omega 6^{\circ}$ : término de Saturno; desde $\Omega 28^{\circ}$ hasta $\Omega 30^{\circ}$ : término de Marte. Escorpio $m:$ desde $m, 0^{\circ}$ hasta $m 7^{\circ}$ : término de Marte; desde $m 24^{\circ}$ hasta $m 30^{\circ}$ : término de Saturno. Sagitario $\chi^{\top}$ : desde $\chi^{\top} 21^{\circ}$ hasta $\chi^{\top} 26^{\circ}$ : término de Saturno; desde $\chi^{\top} 26^{\circ}$ hasta $\chi^{\top} 30^{\circ}$ : término de Marte. Capricornio $\bigvee_{0}$ : desde $\bigvee_{0} 22^{\circ}$ hasta $\bigvee_{0} 26^{\circ}$ : término de Saturno; desde $\bigvee_{0} 26^{\circ}$ hasta $\bigvee_{0} 30^{\circ}$ : término de Marte. Acuario $m$ : desde $m 20^{\circ}$ hasta $m 25^{\circ}$ : término de Marte; desde $m 25^{\circ}$ hasta $m 30^{\circ}$ : término de Saturno. Piscis $)($ : desde $)\left(19^{\circ}\right.$ hasta ( $28^{\circ}$ : término de Marte; desde $)\left(28^{\circ}\right.$ hasta $)\left(30^{\circ}\right.$ : término de Saturno. Véase, por ejemplo, los manuales astrológicos de al-Bīrūnī en: Ramsay-Wright 1934, p. 265 y Abū Ma‘šar (V-9) en: Lemay 1995, p. 325.

${ }^{67}$ Kūšyār Ibn Labbān (Yano 1997, pp. 20-25) enumera solo las estrellas de las constelaciones del zodiaco.

${ }^{68}$ Longitud Cáncer 10;20 y latitud norte 2;40 , Ptolomeo (Toomer 1984, p. 366).

${ }^{69} \mathrm{Ibn}$ 'Azzūz, Kitāb al-fușūl fì ŷam ' al-ușūl, f. 136v; Ibn Riụ̂ān, al-Arba' Maqālāt, f. 24r.

${ }^{70}$ Samsó 1999, pp. 118-119. 
visto un cortador en su horóscopo ${ }^{71}$. Otros textos relatan la ira de Almanzor (hacia 938-1002) contra los mismos astrólogos que le habían avisado de que unos cortadores señalaban la fragilidad de su gobierno ${ }^{72}$.

En los fragmentos de Ibn Abī-l-Riŷāl (2.2) y Kūšyār Ibn Labbān (2.3), cortante alude al potencial para dañar una situación (como en los ejemplos anteriores) y para, incluso, terminar una vida. ¿Cómo se produce esa última facultad? en el contexto de una consulta sobre la duración de una vida, una estrella-corazón-cortador afín a Marte detiene el avance de otro elemento celeste, esto equivale a decir que la estrella-corazón-cortador ha detenido el paso del tiempo terrestre porque la cantidad de grados entre el elemento celeste y la estrella-corazón-cortador representan los años de vida de un individuo.

Por lo que se refiere al vocablo biyabāniyya se observa un cambio en su estructura fonética: en el fragmento del autor oriental Ibn Hibintā (2.4), se lee biyabāniyya, mientras que, en los fragmentos de los autores magrebíes Ibn Abī-l-Riŷāl (2.1), Ibn 'Azzūz (2.5) y el compilador anónimo de Ibn Isḥāq (2.7), la grafía es bābāniyya y bābaniyya. Esto sugiere que, en los manuscritos copiados probablemente en la zona del Magreb, dicho término se empleó en una forma alterada.

Atendiendo a su concepto, biyabāniyya hace las veces de țäbita en el fragmento de Ibn Abī-l-Riŷāl (2.1). Sin embargo, en otros fragmentos, biyabāniyya caracteriza a un tipo concreto de estrella. Así, Ibn Hibintā (2.4) e Ibn 'Azzūz (2.5) relacionan biyabāniyya con las estrellas-corazones. Es cierto que, en Ibn Hibintā, biyabāniyya puede ser igual a tāabita, pero quizá lo reseñable es que, entre los términos biyabāniyya y corazón se da una primera vinculación que se mantiene y aparece estable en Ibn 'Azzūz.

El fragmento de Ibn 'Azzūz es igualmente interesante por otra razón: si lo comparamos con el fragmento de Ibn al-Bannā' (2.6) vemos que las redacciones de ambos son similares y trasladadas, posiblemente, de un mismo original, si bien hay una diferencia notable: en el fragmento de Ibn 'Azzūz, biyabāniyya ha sustituido a țābita; esto conlleva que la palabra entra en una relación diferente con el resto de palabras y modifica su sentido. De este modo, en Ibn al-Bannā' se lee las corazones de los signos fijos (al-burūŷ al-țābita), pero en Ibn 'Azzūz la sustitución ha dado lugar a las corazones de los signos, las bābaniyya.

Creo que lo expuesto muestra cómo el vocablo biyabāniyya pudo adquirir un sentido nuevo hasta construir un paralelismo entre estrella-corazón y estrella-bābanī a partir del modo en que el astrólogo comprendía un

${ }^{71}$ Matar 1992,p. 120.

${ }^{72}$ Samsó 2004, pp. 488-489. 
enunciado, establecía una conexión entre palabras, e interiorizaba un significado.

En el fragmento del compilador anónimo de Ibn Ishāa (2.7), las biyabāniyya son las estrellas que poseen el temperamento de los planetas; aunque es posible argumentar que todas las estrellas tienen afinidad con cierto planeta, en este fragmento se emplea, precediendo a la palabra biyabāniyya, la partícula partitiva $\mathrm{min}^{73}$ utilizada en árabe para expresar una especie y distinguirla de un conjunto.

En algunos de los textos anteriores, el término biyabāniyya ha perdido la significación que tenía en su lengua original porque, probablemente, este préstamo persa, aunque penetró en el vocabulario técnico de los escritos astrológicos árabes, fue empleado esporádicamente por los astrólogos.

\section{CONCLUSIONES}

Hay fuentes en las que se reconoce que las estrellas biyabāniyya son las mismas que las estrellas fijas. Sin embargo, el entorno lingüístico en otras, en concreto Ibn 'Azzūz, muestra que llegaron a tener un propósito astrológico definido valiéndose de una correspondencia con las características propias de un grupo de estrellas: las estrellas-corazones y las estrellas-cortadores.

En consecuencia, para comprender el contenido de estrella biyabāniyya, ha sido necesario establecer y contextualizar las estrellas-corazones y las estrellas-cortadores.

Aunque cuatro en número, El Corazón de Tauro, El Corazón de Leo, El Corazón de Escorpio y El Corazón del Pez, (1) en general, las fuentes astrológicas consideraron las tres primeras indicadores claros en los pronósticos astrológicos por estar situadas cerca del círculo de las influencias celestes, el círculo del zodiaco y (2) en particular, las fuentes primarias de la sección 2 destacaron sus efectos perjudiciales (a) basándose en la doctrina ptolemaica que asigna a esas tres estrellas-corazones una cualidad común afín al temperamento maléfico de Marte, (b) atribuyéndoles la propiedad de cortar o detener la continuidad de la vida de una persona o de su estado y (c) considerándolas iguales, en la potencia, a los términos astrológicos de Saturno y Marte así como a los grados finales de los signos zodiacales que, en su mayoría, gobiernan esos dos planetas maléficos.

Ciertas voces persas no tuvieron un proceso de estandarización en la lengua árabe, así no existe un único tipo para ŷār bujtār y nīmūdār; de igual

\footnotetext{
${ }^{73}$ Wright 1985, parte tercera, p. 137.
} 
modo ocurre con biyabāniyya que fue conocida por bābāniyya y bābaniyya en el norte de África. Tampoco la naturaleza de ŷăr bujtār y biyabāniyya formó parte del saber de los astrólogos de manera tipificada ya que la primera no fue siempre reconocida y biyabāniyya dio lugar a una nueva formulación de su contenido convirtiéndose en exponente de un indicador astrológico con cualidad negativa.

El testimonio de las fuentes estudiadas, la mitad de ellas inéditas, reflejan las distintas recepciones del vocablo biyabāniyya y su configuración diferenciada en la astrología magrebí lo cual incide en nuestro conocimiento del ejercicio del oficio astrológico en el mundo árabe medieval.

\section{BIBLIOGRAFÍA CITADA}

\section{MANUSCRITOS}

al-Battān̄̄, al-Arba 'Maqālāt, Real Biblioteca del Monasterio, San Lorenzo de El Escorial, ms. 969.

Ibn Ab̄̄-l-Riŷāl, Kitāb al-bāri“ fì ahkām al-nuŷūm, Staatsbibliothek, Berlín, ms. Landberg 69, Ahlwardt 5892.

Ibn 'Azzūz, Kitāb al-fuṣūl fì ŷam 'al-uṣull, al-Jizāna al-Ḥasaniyya, Rabat, ms. 1110.

Ibn Hibintā, al-Mugnī fì aḥkām al-nuŷūm, Maktabat al-Zāhiriyya, Damasco, ms. ‘āmm 9354, edición facsímil de Sezgin 1987, vol. I.

Ibn Riḍwān, al-Arba 'Maqālāt, Real Biblioteca del Monasterio, San Lorenzo de El Escorial, ms. 916.

Zarādušt, al-Mawā̄l̄d, Real Biblioteca del Monasterio, San Lorenzo de El Escorial, ms. 939.

\section{FUENTES EDITADAS Y ESTUDIOS MODERNOS}

Burnett, Charles; Yamamoto, Keiji; Yano, Michio (1994), Abū Ma ‘̌ar, The abbreviation of the introduction to astrology. Together with the medieval Latin translation of Adelard of Bath. Edited and translated, Leiden, Brill.

Comes, Mercè (1990), Al-Șüfì como fuente del libro de la "Ochaua Espera" de Alfonso X, en Comes, Mercè; Mielgo, Honorino; Samsó, Julio (eds.), "Ochava Espera" y "Astrofísica": textos y estudios sobre las fuentes árabes de la astronomía de Alfonso X, Madrid, Agencia Española de Cooperación Internacional - Barcelona, Universidad de Barcelona, pp. 11-113. Reimpresión: 2013, en Rius Piniés, Mònica; 
Gómez Muns, Susana (coords.), Homenaje a Mercè Comes. Coordenadas del cielo y de la tierra, Barcelona, Publicacions i edicions de la Universitat de Barcelona, pp. 13-111.

Comes, Mercè (1994), La primera tabla de estrellas documentada en al-Andalus, en Camarasa, Josep Maria; Mielgo, Honorino; Roca, Antoni (eds.), I Trobades d'història de la ciència i de la tècnica, Barcelona, SCHCT, pp. 95-109. Reimpresión: 2013, en Rius Piniés, Mònica; Gómez Muns, Susana (coords.), Homenaje a Mercè Comes. Coordenadas del cielo y de la tierra, Barcelona, Publicacions i Edicions de la Universitat de Barcelona, pp. 123-137.

Díaz-Fajardo, Montse (2011), El capítulo sobre el tasyīr en al-Bāri‘ de Ibn Abī-l-Riŷāl y su traducción alfonsí, "Al-Qanțara. Revista de Estudios Árabes" 32/2, pp. 333-368.

Díaz-Fajardo, Montse (2016), Gestation Times Correlated with Lunar Cycles. Ibn al-Kammād's Animodar of Conception Across North Africa, "Suhayl. International Journal for the History of the Exact and Natural Sciences in Islamic Civilisation" 15, pp. 129-229.

Djebbār, Aḥmad; Aballāgh, Muhammad (2001), Hayāt wa-mu'allafāt Ibn alBannā' al-murrākuš̃ ma 'a nușūs gayr manšūra, Casablanca, Publications de la Faculté des Lettres (Rabat).

Fajr al-Dīn, Ŷawdat (1991), Al-Juwārizmī, Mafātīh al-'ulūm, li-l-imām al-

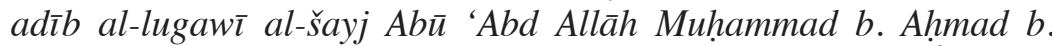
Yūsuf al-kātib al-Juwārizmī, Introducción de Fajr al-Dīn, Ŷawdat, Beirut, Dar al-Manahel.

Forcada, Miquel (1993), Ibn 'Āșim (m. 403/1013), Kitāb al-anwā'wa-l-azmina-al-qawl fì l-šuhūr-(Tratado sobre los anwā' y los tiempos -capítulo sobre los meses-). Estudio, traducción y edición crítica, Madrid, Consejo Superior de Investigaciones Científicas, Instituto de Cooperación con el Mundo Árabe - Barcelona, Instituto "Millás Vallicrosa" de Historia de la Ciencia Árabe (Fuentes Arábico-Hispanas;15).

García Campos, Joaquín (1953), De toponimia arábigo-estelar. Estudio compendiado de los nombres árabes de las constelaciones y estrellas del firmamento y de los accidentes astronómicos más frecuentes, Madrid, Consejo Superior de Investigaciones Científicas, Instituto de Estudios Africanos.

Goldstein, Bernard R.; Chabás, José (1996), Ibn al-Kammād's star list, "Centaurus" 38, pp. 317-334.

Kunitzsch, Paul (1964), Das Fixsternverzeichnis in der „Persischen Syntaxis" des Georgios Chrysokokkes, "Byzantinische Zeitschrift" 57, pp. 382-411. Reimpresión: 1989, The Arabs and the Stars, Aldershot, Ashgate (Variorum Collected Studies Series). 
Kunitzsch, Paul (1980), Two Star Tables from Muslim Spain, "Journal for the History of Astronomy" 11, pp. 192-201. Reimpresión: 1989, The Arabs and the Stars, Aldershot, Ashgate (Variorum Collected Studies Series).

Kunitzsch, Paul (1981), Stelle beibenie, al-kawākib al-biyābān̄̄ya. Ein Nachtrag, "Zeitschrift der Deutschen Morgenländischen Gesellschaft" 131, pp. 263-267. Reimpresión: 1989, The Arabs and the stars, Aldershot, Ashgate (Variorum Collected Studies Series).

Kunitzsch, Paul (1986), The Star Catalogue Commonly Appended to the Alfonsine Tables, "Journal for the History of Astronomy" 17, pp. 89-98.

Reimpresión: 1989, The Arabs and the Stars, Aldershot, Ashgate (Variorum Collected Studies Series).

Kunitzsch, Paul (1987), Al-manāzil, Encyclopaedia of Islam, Leiden, Brill, vol. VI, pp. 374-376. Reimpresión: 1989, The Arabs and the Stars, Aldershot, Ashgate (Variorum Collected Studies Series).

Kunitzsch, Paul (1993), Al-Nudjūm, Encyclopédie de l'Islam, Leiden, Brill, vol. VIII, pp. 99-107.

Kunitzsch, Paul (1993a), The Chapter on the Fixed Stars in Zarādusht's Kitāb al-mawālìd, "Zeitschrift für Geschichte der Arabisch-Islamischen Wissenschaften" 8, pp. 241-249. Reimpresión: 2004, Stars and Numbers, Aldershot, Ashgate (Variorum Collected Studies Series).

Labarta, Ana; Mestres, Àngel (2005), Mūsà ibn Nawbajt, Kitāb al-azmina wa-l-duhūr. Tratado de astrología mundial, Valencia, Universidad de Valencia.

Lemay, Richard (1995), Abū Ma ‘̌ar al-Balkhī [Albumasar]. Kitāb al-madkhal al-kabīr ilà 'ilm ahkām al-nudjūm. Liber introductorii maioris ad scientiam judiciorum astrorum. Édition critique, Nápoles, Istituto Universitario Orientale.

Matar, Zaynab (1992), The Chapter on Death-Prediction (qat' 'quțū') from the Kitāb fară al-mahmūm by Ibn Ṭāwūs, "Bulletin d'Études Orientales" 44, pp. 120-125.

Mestres, Àngel (1996), Maghribī Astronomy in the 13 ${ }^{\text {th }}$ Century: A Description of Manuscript Hyderabad Andra Pradesh State Library 298, en Casulleras, Josep; Samsó, Julio (eds.), From Baghdad to Barcelona: Studies in the Islamic Exact Sciences in Honour of Prof. Juan Vernet, Barcelona, Instituto "Millás Vallicrosa" de Historia de la Ciencia Árabe, pp. 383-443 (Anuari de Filologia; 19, B-2),

Mestres, Àngel (1999), Materials andalusins en el zīj d'Ibn Isḥ̄ā al-Tūnisī. Edició crítica i estudi del manuscrit 298 de la Andra Pradesh State Library de Hyderabad, Barcelona, Universitat de Barcelona (tesis doctoral). 
Parra, María José (2012), La tabla de estrellas de Ibn al-Raqqām en una versión árabe del almanach perpetuum de Abraham Zacuto, "Archives Internationales d'Histoire des Sciences/International Archive of the History of Science" 62/168, pp. 27-41.

Pingree, David (1976), Dorotheus Sidonius, Carmen astrologicum. Interpretationem arabicam in linguam anglicam versam una cum Dorothei fragmentis et graecis et latinis, Lipsia, Biblioteca scriptorum graecorum et romanorum Teubneriana.

Pingree, David (1989), Classical and Byzantine Astrology in Sassanian Persia, "Dumbarton Oaks Papers" 43, pp. 227-239.

Ramsay-Wright, Robert (1934), The Book of Instruction in the Elements of the Art of Astrology by Abū-l-Rayhān Muhammad ibn Ahmad al-Bīrūnī: The Translation Facing the Text, Londres, Luzac \& Co.

Rico y Sinobas, Manuel (comp.) (1863-1867), Libros del saber de astronomía del Rey D. Alfonso X de Castilla. Copilados, anotados y comentados por Manuel Rico y Sinobas, Madrid, E. Aguado.

Robbins, Frank Egleston (ed.) (1980), Ptolemy, C., Tetrabiblos: Edited and Translated into English, Cambridge, Massachusetts, Harvard University Press. (1. ${ }^{\mathrm{a}}$ ed. 1940).

Samsó, Julio (1999), Horoscopes and History: Ibn 'Azzūz and his Retrospective Horoscopes Related to the Battle of El Salado (1340), en Nauta, Lodi; Vanderjagt, Arjo (eds.), Between Demonstration and Imagination: Essays in the History of Science and Philosophy Presented to John D. North, Leiden, Brill, pp. 101-124.

Samsó, Julio (2000), Maslama al-Majrịți and the Star Table in the Treatise De Mensura Astrolabii, en Folkerts, Menso; Lorch, Richard (eds.), Sic itur ad astra: Studien zur geschichte der mathematik und naturwissenschaften, Wiesbaden, Verlag, pp. 506-522. Reimpresión: 2007, Astronomy and Astrology in al-Andalus and the Maghrib, Aldershot, Ashgate (Variorum Collected Studies Series).

Samsó, Julio (2004), Cuatro horóscopos sobre muertes violentas en al-Andalus y el Magrib, en Fierro, Maribel (ed.), De muerte violenta. Política, religión y violencia en al-Andalus. Estudios onomástico-biográficos de al-Andalus, Madrid, Consejo Superior de Investigaciones Científicas, vol. XIV, pp. 479-519. Reimpresión: 2008, Astrometeorología y astrología medievales, Barcelona, Publicacions i Edicions de la Universitat de Barcelona.

Schjellerup, Hans C.F.C. (1874), Description des étoiles fixes composée au milieu du dixième siècle de notre ère par l'astronome persan 'Abdal-Rahmān al-Süfĩ: traduction littérale avec des notes, San Petersburgo, Académie Impériale des Sciences. Réimpression par: Sezgin, 
Fuat (1986), Fráncfort del Meno, Institut für Geschichte der Arabisch-Islamischen Wissenschaften.

Sezgin, Fuat (1987), Ibn Hibintā, al-Mughn̄ fì ahkām al-nujūm (The Complete Book on Astrology), Fráncfort del Meno, Publications of the Institute for the History of Arabic-Islamic Science.

Toomer, Gerald J. (trad.) (1984), Ptolemy's Almagest, Princeton, Princeton University Press.

Vernet, Juan; Català, María Asunción (1965), Las obras matemáticas de Maslama de Madrid, "Al-Andalus" 30/1, pp. 15-45.

Wright, William (1985), A Grammar of the Arabic Language: Translated from the German of Caspari and edited with Numerous Additions and Corrections, Cambridge, University Press. (1. . ed. 1859-1862, reprinted 1985).

Yano, Michio (ed.) (1997), Kūšyār ibn Labbān's Introduction to Astrology: Edited and translated, Tokio, Institute for the study of languages and cultures of Asia and Africa.

Fecha de recepción del artículo: agosto 2016

Fecha de aceptación y versión final: septiembre 2017 